\title{
CHARACTER BUILDING BASED ON LOCAL WISDOM IN THE FILM TITLED TANDA TANYA "?"
}

\author{
Nur Alfi Farikhah, Ratna Handayani Pramukti, Vena Nur Litasari, Ratna Hidayah \\ Universitas Sebelas Maret \\ alfi.farikhah17@gmail.com
}

\section{Article History}

accepted 30/09/2018

approved 12/10/2018

published 30/10/2018

\section{Keywords}

character, education, culture.

\begin{abstract}
Character is very important in an effort to reflect cultural values that are applied through a culture of positive habits in everyday life such as honesty, trust, tolerance and caring for fellow human beings in the community. The value of local wisdom is not a barrier to progress in the global era, but still maintains cultural values that have been embedded in the surrounding community. Therefore, fostering the values of local wisdom is a strategic step in the effort to build the character of the nation. This article proposes to discuss the cultivation of cultural values through a tolerance attitude based on local wisdom in the surrounding environment as a community character reinforcement being appropriate to the cultural values which are inspired by the film titled Tanda Tanya "?". The film describes the life that has been acculturated, then shows the assimilation and pluralism that exist in the lives of people in Indonesia. This film has educational purpose containing knowledge and learning that occur around the lives of diverse cultural communities.
\end{abstract}

Social, Humanities, and Education Studies (SHEs): Conference Series https://jurnal.uns.ac.id/shes

p-ISSN 2620-9284 e-ISSN 2620-9292 


\section{PENDAHULUAN}

Pendidikan karakter merupakan bentuk kegiatan dalam pendidikan yang di dalamnya terdapat suatu tindakan/perbuatan manusia yang mendidik, mengarahkan, membimbing dan membentuk kepribadian individu generasi selanjutnya. Tujuan pendidikan karakter adalah untuk membentuk penyempurnaan diri individu secara terus-menerus dan melatih kemampuan diri demi menuju ke arah hidup yang lebih baik. Menurut Rahayu (2012:12-13) menyatakan bahwa dalam pendidikan karakter sendiri meliputi 18 nilai yaitu religius, jujur, toleransi, disiplin, kerja keras, kreatif, mandiri, demokratis, rasa ingin tahu, semangat kebangsaan, cinta tanah air, menghargai prestasi, bersahabat/komunikatif, cinta damai, gemar membaca, peduli lingkungan, peduli sosial, dan tanggung jawab yang diharapkan dapat dimiliki oleh generasi pemuda Indonesia.

Almusafiri (2016:3) menyatakan bahwa "Pendidikan karakter mempunyai kaitan erat dengan komponen-komponen meliputi pengetahuan moral tradisi, penalaran moral, belas kasih dan altruisme, serta kecenderungan moral." Sehingga perlu kita sadari bahwa indonesia memiliki keanekaragaman yang sangat luas, maka sebagai makhluk sosial tentu selalu hidup berdampingan baik dalam suatu kelompok suku, ras dan agama. Terdapat banyak pelajaran dan pengetahuan tentang budaya di Indonesia terutama agama dan keyakinan di Indonesia berbeda-beda sehingga harus ada pendidikan karakter yang dapat membangun toleransi terhadap orang-orang yang berbeda agama khususnya. Pada kenyataannya, karakter pemuda saat ini kurang mendapat perhatian dan bimbingan dari lingkungan masyarakat, sehingga terjadi degradasi moral. Dengan adanya pendidikan karakter dalam masyarakat ini tentu akan membantu melestarikan budayanya dengan baik. Selain itu, melihat budaya dari masa ke masa kian terkikis oleh perkembangan zaman yang menuntut generasi untuk mengikuti arus perkembangan, sehingga lupa akan identitas kebangsaan dan warisan budaya asalnya. Nilai kebudayaan lokal harus sangat diperhatikan dan dipandang sebagai nilai yang berharga dalam menghadapi perkembangan zaman karena masyarakat tidak lepas dari tradisi dan budaya yang sudah melekat secara turun temurun.

Berdasarkan uraian tersebut, maka permasalahan yang akan dibahas dalam artikel ini adalah bagaimana nilai-nilai budaya yang ada dalam sebuah film Tanda Tanya "?" dan bagaimana pengembangan pendidikan budaya dan karakter dari film Tanda Tanya "?". Hal ini bertujuan untuk menanamkan nilai-nilai karakter budaya melalui sikap, seperti religius, jujur, toleransi, disiplin, kerja keras, kreatif, mandiri, demokratis, rasa ingin tahu, semangat kebangsaan, cinta tanah air, menghargai prestasi, bersahabat/komunikatif, cinta damai, gemar membaca, peduli lingkungan, peduli sosial, dan tanggung jawab di masyarakat yang berbasis kearifan lokal.

\section{HASIL DAN PEMBAHASAN}

Dalam upaya untuk mendukung keberhasilan pendidikan karakter baik dalam keluarga maupun masyarakat diharapkan mampu memberikan bimbingan dasar mengenai aturan dan norma yang sudah ada dalam budayanya secara turun-temurun. Dunia yang kita tinggali memang tidak lagi bisa dibagi-bagi ke dalam kotak-kotak kehidupan yang saling terpisah. Dari hal tersebut, sangat diperlukan karakter yang dapat bersahabat dan peduli baik sesama ataupun berbeda suku, ras, dan agama dalam budaya di masyarakat karena kehidupan sekarang sudah banyak pembauran kehidupan sesuai dengan perkembangan zaman, seperti munculnya perilaku positif dan negatif pasti ada dalam kehidupan yang global sehingga tidak mudah dalam mengubahnya menjadi perilaku yang positif secara keseluruhan (Saputra, 2016: 2).

Dalam film Tanda Tanya "?" yang bertemakan kerukunan antar umat beragama, dengan dikisahkan kehidupan suatu lingkungan yang masyarakatnya multi agama dan etnis yang melakukan pekerjaan maupun kegiatan sehari-hari secara berdampingan. 
Film ini merupakan karya Hanung Bramantyo yang berangkat dari salah satu realitas nyata yang ada di masyarakat Indonesia, Hanung Bramantyo yang dibantu oleh penulis naskah skenario yang bernama Titin Watimena akhirnya dapat mengembangkan menjadi sebuah film yang di dalamnya banyak terdapat toleransi agama, sehingga diproduksi menjadi sebuah film yang berjudul Tanda Tanya "?". Dalam film Tanda Tanya "?" menceritakan kisah sebagai berikut :

Keberagaman dan toleransi merupakan dua hal yang saling terkait, terutama jika menyangkut masalah keagamaan dan suku bangsa. Indonesia sebagai negara berpenduduk mayoritas Muslim dengan berbagai macam etnis dan kebudayaan, memiliki banyak kisah perihal toleransi yang menarik untuk diangkat dalam tayangan layar lebar. Hanung Bramantyo sebagai seorang sutradara kawakan tergerak untuk dapat menghadirkan kisah dengan latar belakang perbedaan ini kepada masyarakat Indonesia. Film ini dirilis pada 7 April 2011 di bioskop-bioskop Indonesia.

Film ke 14 Hanung Bramantyo ini mengisahkan tentang konflik keluarga dan pertemanan yang terjadi di sebuah area dekat Pasar Baru, dimana terdapat Masjid, Gereja dan Klenteng yang letaknya tidak berjauhan, dan para penganutnya memiliki hubungan satu sama lain.

Dikisahkan kehidupan keluarga-keluarga yang hidup ditengah perbedaan etnis dan agama. Hidup berdampingan dalam lingkungan yang dikelilingi oleh Mesjid, Gereja dan Klenteng. Keluarga Tan Kat Sun, pemilik restoran Canton masakan Cina yang walaupun menyediakan masakan tidak halal, namun dengan kesadaran dan toleransinya yang tinggi, ia juga mengakomodir kebutuhan makanan halal bagi pelanggan muslim-nya. Walaupun banyak mendapat ketidakyakinan akan kehalalan masakan halal-nya, ia berbesar hati dan konsisten untuk tetap menghargai karyawan, tetangga maupun pelanggan muslimnya. Menuk bekerja dalam lestoran restoran Canton, dan waktu beribadah tetap sesuai dengan keyakinan agama masing-masing. Di dalam restoran Canton Menuk dan Liem melakukan sholat dan sembahyang di tempat yang bersebelahan dalam satu ruangan didalam restoran.

Rika, seorang mualaf Kristen, janda dengan seorang anak, yang tetap mengajarkan iman islam kepada Abi anaknya bahkan mampu mendatangkan kembali orang tuanya kerumahnya dalam syukuran khatam Al-Quran putra semata wayangnya. Tersirat dikisahkan Rika memiliki hubungan dengan Surya pemuda muslim yang bersedia memerankan tokoh Yesus yang disiksa dan disalib dalam drama Paskah juga sebagai Yosef, suami Maria ibu Yesus dalam drama Natal.

Rasa toleransi beragama yang tinggi dari sang majikan membuat Menuk, satusatunya anak buahnya yang berjilbab, sangat loyal terhadap Tan Kat Sun. Namun, Soleh, suami Menuk, cemburu pada Ping Hen alias Hendra, anak Tan Kat Sun. Latar belakang anugrah saling mencintai dalam perbedaan agama yang pernah dijalin Hendra dan Menuk membuat pasangan suami-istri ini sering berselisih paham.

Lewat film yang diilhami oleh kisah nyata ini, Hanung Bramantyo mencoba mengumandangkan pesan tentang toleransi beragama yang dinilainya kian luntur belakangan ini. Film yang mengedukasi kaum muda yang sudah terkontaminasi jalan pikirannya bahwa berbeda itu haram, untuk kembali diluruskan sehingga dapat memaknai indahnya perbedaan dalam kasih.

Seperti judulnya Tanda Tanya "?", film ini pun meninggalkan tanda tanya dalam hati saya setelah menyaksikannya. Sebuah tanda tanya sangat besar sepertinya. Tanda tanya yang tersisa seperti dalam tag-line film ini: "Masih pentingkah kita berbeda?" di negeri yang pada masa merebut kemerdekaannya, telah menumpahkan darah anak-anak bangsa yang tidak hanya dari satu agama maupun etnis.

Hanung Bramantyo dalam film ini sangat jeli memperhatikan hal- hal kecil. Banyak dijumpai gambar-gambar yang dapat memperkuat visualisasi dan tata artistic. Setiap lokasi memiliki detil-detil kecil yang teliti sehingga memberi kesan sangat realistis. 
Walau bukan film komedi tetapi beberapa adegan sanggup membuat tertawa karena adegan-adegan tersebut sering terjadi dalam keseharian kita. Ketika tertawa, film ini membuat penonton menertawakan realitas Indonesia sebagai negara plural yang tidak siap menjadi pluralis. film ini memperkenalkan tentang karakter dan latar belakang tokoh-tokoh film :

1. Menuk

Seorang wanita yang bekerja di restoran cina "Chanton Chinese Food" yang dikelola oleh keluarga Tan Kat Sun. ia taat menjalankan ibadahnya dan taat kepada suaminya yaitu Soleh. Pekerja keras dan memiliki pendirian teguh.

2. Sholeh

Sholeh adalah suami dari menuk, yang tak kunjung mendapat pekerjaan hingga pada puncaknya ia meminta cerai dari menuk. Namun berkat kesabaran dan keyakinan dari menuk ia berhasil mendapatkan pekerjaan sebagai seorang anggota banser NU (Nahdatul Ulama). ia meninggal ketika sedang mengamankan gereja pada waktu malam natal.

3. Surya

Seorang pria beragama Islam yang berprofesi sebagai seorang aktor. ia memerankan tokoh Yesus ketika malam paskah.

4. Rika

la berprofesi sebagai penjaga toko buku. Seorang janda beranak satu yang baru pindah agama menjadi Katolik. la tidak mengajak anaknya yang beragama Islam untuk pindah agama juga.

5. Baim

Anak dari seorang janda yang bernama Rika yang beragama katolik, sedangkan dia beragama Islam.

6. Hendra

Anak laki-laki Tan Kat Sun yang juga beragama Kong Hu Chu. Sifat hendra yang sangat berbeda dengan ayahnya membuat ia sering terlibat perkelahian dengan etnis dan agama lain.

7. Tan Kat Sun

Seorang pria beragama Kong $\mathrm{Hu}$ Chu merupakan pemilik restauran "Chanton Chinese Food". la sangat menghormati dan menghargai keberadaan umat lain. Misalkan memberikan waktu untuk shalat kepada para pegawainya yang sebagian besar pemeluk agama Islam termasuk kepada si Menuk. la juga selalu memisahkan peralatan untuk memasak makanan.

8. Lim Giok Lie

Istri dari remilik restoran cina yang mempunyai sikap lemah lembut dan taat kepada suaminya yang selalu sabar menghadapi anaknya Koh Hendra yang sangat keras kepala dan angkuh.

9. Ustadz Wahyu

Sabar, bijaksana, toleran dan penyayang ini adalah sikap dari seorang Ustadz Wahyu yang sehari-harinya menjadi imam masjid.

10. Room Djiwo

Pastur dalam sebuah gereja santo paulus yang mempunyai sifat toleran karena dia memberikan kesempatan bagi seorang muslim untuk memerankan drama paska menjadi Yesus.

11. Doni

Seorang pemuda yang menyukai seorang wanita yang baru saja berpindah agama, tetapi dia tidak bisa mendapatkan wanita tersebut (Rika) karena wanita tersebut menyukai seorang laki-laki yang bernama surya.

Di balik film Tanda Tanya "?" yang disutradarai Hanung Bramantyo ini ada hikmah yang dapat kita petik melalui pesan tersirat yang kuat terutama perihal toleransi di tengah-tengah keberagaman. Dalam keberagaman terdapat nilai-nilai yang 
dianggap berharga atau penting yang mengedepankan keberagaman, kesetaraan, perbedaan, toleransi, humanisme, keadilan, demokrasi, dan pluralisme demi terwujudnya kehidupan bermasyarakat, berbangsa, bernegara, dan beragama di Indonesia dengan terciptanya suasana yang damai, tentram, dan bahagia, dengan tetap menjunjung tinggi persatuan, kesatuan, dan persaudaraan. dimana Indonesia merupakan negara berpenduduk mayoritas Muslim dengan berbagai macam etnis dan kebudayaan untuk menghargai keyakinan agama kita masing masing. dari hal tersebut dapat kita lihat nilai-nilai yang terdapat dalam film Tanda Tanya "?" yaitu sebagai berikut:

1. Nilai Toleransi

Toleransi beragama menurut Khalikin dan Fathuri (2016:14) adalah "Toleransi antar umat beragama yaitu sikap maupun perilaku terhadapa hal-hal yang bersifat keagamaan meliputi : keyakinan, pemikiran, maupun perilaku keagamaaan umat beragama yang mencerminkan toleransi terhadap umat beragama lain baik perorangan maupun kelompok.

Pada adegan film dalam keluarga Tan Kat Sun, pemilik restoran Canton masakan Cina yang walaupun menyediakan masakan tidak halal, namun dengan kesadaran dan toleransinya yang tinggi, ia juga mengakomodir kebutuhan makanan halal bagi pelanggan muslim-nya. Walaupun banyak mendapat ketidakyakinan akan kehalalan masakan halal-nya, ia berbesar hati dan konsisten untuk tetap menghargai karyawan, tetangga maupun pelanggan muslimnya.

Berdasarkan adegan tersebut pesan yang dapat kita ambil yaitu oleh pentingnya menghargai dan menghormati keyakinan agama dalam kehidupan kemasyarakatan yang diaplikasikan dalam sikap dan perilaku baik perorangan maupun kelompok.

2. Nilai Pluralisme

Menurut Rahman dalam jurnalnya yang berjudul Islam Dan Pluralisme (2014: 405) "Pluralisme adalah keadaan atau paham dalam masyarakat yang majemuk bersangkutan dengan system social politiknya sebagai budaya yang berbeda-beda dalam satu masyarakat."

Bentuk pluralisme yang terdapat dalam film Tanda Tanya "?" yaitu seperti yang terdapat dalam adegan film pada saat Menuk dan Liem melakukan sholat dan sembahyang di tempat yang bersebelahan dalam satu ruangan didalam restoran. Dan kehidupan masyarakat didalamnya berdampingan dalam lingkungan yang dikelilingi oleh Mesjid, Gereja dan Klenteng.

Berdasarkan adegan tersebut pesan yang dapat kita ambil yaitu antar umat beragama dapat hidup berdampingan dengan tetap mempertahankan dan melaksanakan ajaran agama masing-masing serta tetap manjaga perbedaan etnis dan agama tetap bisa terjaga dengan baik.

3. Nilai Demokrasi

Demokrasi adalah nilai, menurut Tim Abdi Guru (dalam Yuliana (2013: 15)) mendefinisikan bahwa "Demokrasi merupakan sebuah nilai atau pandangan hidup. Demokrasi sebagai sebuah nilai tidak hanya berkaitan dengan urusan kepentingan saja, tetapi juga bisa dipraktekkan dalam kehidupan sehari-hari baik dalam keluarga, sekolah, maupun dalam masyarakat."

Bentuk demokrasi yang terdapat dalam film Tanda Tanya "?" yaitu pada saat Ustadz Wahyu melerai perkelahian yang terjadi antara sekelompok anak-anak masjid dengan Hendra.

Berdasarkan adegan tersebut pesan yang dapat kita ambil yaitu sikap yang menunjukkan bahwa kita sebagai seorang manusia memiliki hak dan perlakuan yang sama, tidak membedakan ras, etnis, agama, dan strata sosial yang ada di dalam kehidupan bermasyarakat dan bernegara. Kita harus saling bahu-membahu dan menghindari segala sesuatu yang dapat menimbulkan konflik. 
4. Nilai Kesetaraan

Kesetaraan sosial adalah tata politik sosial dimana semua oran yang berda dalam suatu masyarakat atau kelompok tetentu memiliki status yang sama. (wikipedia.com)

Bentuk kesetaraan yang terdapat dalam film Tanda Tanya "?" yaitu seperti yang terdapat dalam adegan film pada saat dengan Surya pemuda muslim yang bersedia memerankan tokoh Yesus yang disiksa dan disalib dalam drama Paskah juga sebagai Yosef, suami Maria ibu Yesus dalam drama Natal. dan Doni meminta membatalkan drama karena Surya seorang muslim. Romo Djiwo juga menyampaikan, tidak mungkin keimanan dan agama itu hancur oleh sebuah adegan drama, melaikan keimanan dan agama itu akan hancur disebabkan oleh kebodohan penganutnya, makanya janganlah kita menjadi orang yang bodoh.

Berdasarkan adegan tersebut pesan yang dapat kita ambil yaitu perlunya memiliki nilai kesetaraan mencangkup hak yang sama dibawah hukum, seperti memiliki hak yang sama untuk bebas memilih sesuai pilihannya, tetapi tidak merubah keyakinan dan akhlak sebagai umat beragama sehingga tetap toleransi dan kesetaraan tiap umat beragama yang hidup berdampingan.

5. Nilai Humanisme

Humanisme adalah istilah umum untuk berbagai jalan pikiran yang berbeda yang memfokuskan dirinya ke jalan keluar umum dalam masalah-masalah atau isu-isu yang berhubungan dengan manusia. Humanisme dalam arti filsafat diartikan sebagai paham yang menjunjung tinggi nilai dan martabat manusia sedemikian rupa sehingga manusia menempati posisi yang sangat sentral dan penting dalam hidup sehari-hari (Abidin dalam Ulya (2017: 74-93)).

Bentuk humanisme yang terdapat dalam film Tanda Tanya "?" yaitu seperti yang terdapat dalam adegan film pada saat Soleh menjaga di gereja, ia rela memeluk dan membawa lari bom dari dalam Gereja ke halaman dan mengorbankan dirinya demi keselamatan jemaat dan orang-orang yang ada di Gereja tersebut.

Berdasarkan adegan tersebut pesan yang dapat kita ambil yaitu pentingnya sikap kemanusiaan sebagai masyarakat yang berbudaya untuk tetap menjaga keharmonisan dan keselamatan dalam hidup berdampingan antar umat beragama.

\section{SIMPULAN}

Berdasarkan uraian di atas, dapat disimpulkan bahwa dengan menelaah film Tanda Tanya "?" terdapat beberapa hal yang terkandung dalam membangun nilai-nilai budaya dalam pendidikan, khususnya dalam kehidupan bermasyarakat yang berbasis kearifan lokal di lingkungan sekitar. penguatan karakter masyarakat yang sesuai nilai-nilai karakter budaya yang merupakan inspirasi dari film Tanda Tanya "?" yaitu pentingnya penanaman nilai-nilai karakter budaya melalui sikap toleransi, pluralisme, demokrasi, kesetaraan, dan humanisme dalam kehidupan yang sudah terakulturasi dan pluralisme yang ada dalam kehidupan masyarakat di Indonesia.

\section{DAFTAR PUSTAKA}

Khalikin dan Fathuri. (2016). Toleransi Beragama di Daerah Rawan Konflik. Jakarta: Puslitbang Kehidupan Keagamaan.

Musafiri, M. R. A. (2016). Peran Kearifan Lokal bagi Pengembangan Pendidikan Karakter pada Sekolah Menengah Atas. Jurnal Darussalam: Jurnal Pendidikan, Komunikasi dan Pemikiran Hukum Islam. Vol. VIII, No. 1: 1-19. Banyuwangi: Institut Agama Islam Darussalam (IAIDA) Banyuwangi.

Rahman, M. S. (2014). Islam Dan Pluralisme. Fikrah. Vol. 2, No. 1: 405. Pamekasan: Pascasarjana STAIN Pamekasan. 
Rahayu, M. P. (2012). Nilai-nilai Pendidikan Karakter pada Materi Ajar Buku Kreatif Berbahasa dan Bersastra Indonesia Untuk SMP Kelas VII Terbitan Ganeca. Jurnal Publikasi Hal. 12-13. Fakultas IImu Keguruan dan Pendidikan. Surakarta: Universitas Muhammadiyah Surakarta.

Saputra, H. (2016). Pengembangan Mutu Pendidikan Menuju Era Global. CV Smile's Indonesia.

Ulya, F. (2017). Nilai-Nilai Pendidikan Multikultural Dalam Film "Tanda Tanya" Karya Hanung Bramantyo [Skripsi]. Purwokerto: Islam Institut Agama Islam Negeri Purwokerto.

Yuliana, R. (2013). Implementasi Nilai-nilai Demokrasi dalam Pembelajaran Pendidikan Kewarganegaraan di SMP Negeri 3 Grinsing Batang [Skripsi]. Semarang: Universitas Negeri Semarang. 